\title{
Challenging Convergences in Lay Thought and STS Practice: A Reply to My Critics
}

\author{
TAYLOR DOTSON ${ }^{1}$ \\ New Mexico Institute of Mining and Technology
}

\begin{abstract}
Keywords
permissionless innovation; technological determinism; impairment; politics of artifacts; intelligent trial and error
\end{abstract}

David Hess and Sujatha Raman have penned what might seem to be fairly damning critiques of my proposal to view technological determinism and permissionless innovation as psychocultural barriers to the democratization of technology. They quickly chop down my suggestion to look to fields like communications and social psychology for help in developing oppositional rhetorical strategies. Some of their concerns are quite reasonable, though I will contend that they are not as damaging to my proposal as they suggest. Other criticisms, however, appear to be rooted in pretty extreme interpretations of my argument. Whatever the cause of the miscommunication, I relish the chance to challenge the more unfortunate renderings of my position. Furthermore, I will turn a critical eye back toward the commentators. Not only do they neglect the technological or material concerns that I raised in my paper, but also fail to seriously engage with the potential incremental benefits of developing and prudently deploying the communicative tools that I describe.

A fairly typical defensive response to any claim that some gap exists in the existing literature or that some practice is missing from current scholarly activity is "Where have you been?" Just such a response is one of the main thrusts of Raman's (2015) critique: "Battles over some abstraction called 'technological determinism' seem a distant memory." She cites her own work within a rich research community-including responsible innovation, engagement with technoscientific policy regimes, and laboratory interventions-in order to depict my assertion that a preoccupation with nomological forms of technological determinism has continued to infect STS scholarship as out-of-touch with more recent academic realities.

Contrary to Raman's (2015) interpretation of my fairly minor extension of claims already made by other science and technology studies (STS) scholars (see Wyatt 2008; Dafoe 2015), I did not intend to imply that absolutely nothing was being done in the field regarding normative

Taylor Dotson, Email: tdotson@nmt.edu

Copyright (c) 2015 (Taylor Dotson). Licensed under the Creative Commons Attribution Non-commercial No Derivatives (by-nc-nd). Available at estsjournal.org. 
forms of technological determinism. Rather, I only meant to suggest that more could be done. On the one hand, I wish to join in applauding the efforts of Raman and others doing the hard work of striving toward more democratic innovation. On the other hand, many of the efforts she references seem largely continuous with earlier iterations of technology assessment and engaged scholarship, and I was not unaware of them. I still think that STS scholars could broaden their thinking regarding how to strategize toward more democratic technological societies, targeting governing mentalities like technological determinism and permissionless innovation more directly, more frequently, and across a larger number of venues and contexts. As excellent as ongoing experiments with deliberative forums and the other intuitional engagements cited by Raman are, such efforts do not exhaust the full range and depth of political interventions that STS scholars could be supporting.

Raman (2015) and Hess (2015) read my paper as advocating an unreasonable degree of methodological narrowness and strategic naiveté. Raman reduces my exploration of possible directions for future research and strategic undertakings to a single program of "building counter-narratives." Hess appears to accuse me of promoting "a methodology restricted to...'culturalism' [which] can result in 'theory somnambulism.'” However, I see my recommendation as more modest, entailing "drawing upon and extending" research lines within social psychology and communications (Dotson 2015). While my phrasing is up for multiple interpretations, I had hoped that most readers would not confuse "drawing upon and extending" with a call for an uncritical or naïve embrace of these disciplines' outlooks and methodologies. Nor did I anticipate that readers might see my analysis of permissionless innovation as somehow asserting that it is "a sui generis or exogenous cultural mentality" (Hess 2015). Indeed, I begin my paper by recognizing that non-democratic technological decision making results from myriad cultural, political, material, and economic (hence structural) forces but state that I would limit the scope of my paper to what I term as the "cognitive" or "psychocultural" barriers. Moreover, I describe these psychocultural barriers as rooted in sociomaterial experience and, therefore, tied to the social actions of both elites and lay persons that scaffold those sociomaterial experiences.

In spite of allusions to the contrary, the more "holistic" analysis that Hess (2015) outlines in his commentary is exactly the kind of work that I saw my paper as advocating for. Although a major focus of my paper was on relaying findings regarding strategies like "broker frames" and "parsimonious counter-narratives," I did not intend to depict such activities as more than just one component of a broader program working toward democratization. I am in total agreement with Hess's demand that research more often focus on learning from and aiding social movement strategizing to lessen barriers in the "political and industrial opportunity structure." Targeting technocratic governing mentalities through communicative interventions need not come at the cost of other levels of intervention and analysis.

I regret that I offered only passing references to the fact that citizens' beliefs regarding the obligatoriness of technologies are rooted in the strength of cultural and material systems whose momentum can be partly attributed to the actions and decisions of elites, including actions situated in and constrained by neo-liberal structures. Certainly it is obvious that the whole matrix of institutions and practices that compose the contemporary political order in affluent 
technological societies ought to be put under the microscope in STS analyses whenever possible. Even though I did not attend to this matrix in detail in my paper, I did urge STS scholars to inquire into how dominant (and elite dominated) sociotechnical networks might help solidify certain political orders-an avenue for political action in the spirit of Winner (1980) that Hess (2015) overlooks. Indeed, the most interesting feature of the commentaries is that, for all the emphasis on structure and agency, materiality is nearly totally absent-even though Hess himself cites Winner in noting that "technology is legislation."

Raman (2015) interpreted my paper as recommending that pro-technological-democracy counter-narratives be developed in a top-down and insular way, going so far as to suggest that it would devolve into an elite-driven, non-deliberative exchange of ideological sound-bites with political opponents. However, I did not mean to suggest that social scientists ought to be so bold or overconfident as to believe that they could develop effective frames or counter-narratives wholly absent the input or participation of lay persons, or that any given rhetorical tool would be unchanging or necessarily dogmatic. I join Charles Lindblom (1990) in viewing the appropriate role of social analysts as supplementary to rather than independent of lay inquiry; I am no advocate of technocracy. That said, social scientists must have something to contribute to lay strategizing toward the strengthening of technological democracy. Otherwise they should consider the possibility that they might ultimately do more good in the world by leaving their academic work behind and becoming activists.

My paper proposes that one of those "somethings" would be to supply more aid to the project of defeating political opponents of democratic technological decision making in the battle of narratives and framings and, eventually, working to partly reverse the degree to which many citizens' thinking about technology and society is impaired. Perhaps Raman would find such talk presumptuous, but I do not mean to argue that STS scholars always and everywhere know better than lay persons. Indeed, the source of my suspicion of public impairment does not rest in some god trick in which I claim to know how the entirety of the public experiences technology-as Raman (2015) quite uncharitably suggests. Rather, from where I am situated and through my social interactions and observations, I see too much convergence in thought and speech among a significant segment of the public regarding technology - a significant enough deviation from the state of disagreement and heated conflict elsewhere in life to suggest the existence of widespread impairment in thought (see Lindblom 1990, 71-75). While Raman implies that I think that oppositional thinking and speech regarding non-democratic innovation is wholly absent, my argument really rests on the claim that there easily could be more of it.

Raman (2015), however, contends that the strategies that I suggest to be potentially fruitful for beating "libertarians in the competition for public attention" in the "marketplace of ideas" are anything but democratic. From the perspective of ideal deliberative-democratic theory she is probably correct. Most STS scholars would likely argue that engaging the public over the proper scope and extent of technological governance would ideally occur in speech settings that afford the maximum degree of plural and multiple publics participating in significant ways and even "talking back." The democratic exercises exploring what such settings would look like and how they would function are largely laudable. At the same time, might narrowly focusing on 
such exercises risk rendering technological democracy not unlike nuclear fusion: always thirty years on the horizon? In the absence of the wider implementation of deliberative democracy, challenging libertarian framings and increasing the competitiveness of the "marketplace of ideas" remains an incremental enhancement of the relatively thin democracies in which we citizens of affluent western nations find ourselves. Even more, I wonder if such an incremental step might even be a precondition for achieving critical mass for the kinds of political activities Raman sees as properly democratic.

Most lamentable, from my perspective, is that neither commentary really engages with the substance of my proposals. My final suggestion that STS scholars could inquire into how the embodied experience of contemporary sociotechnical networks might lead some significant portion of the public to value technological liberty over technological democracy was almost totally ignored. Might it be that experiential elements of certain contemporary technological systems, like highways and big-box shopping, do as much as advertising, the (mis)education of youth, and neoliberalism to lead far too many citizens to put their faith in the myth of the heroic and unfettered innovator rather than demanding more democratic innovation? Might the unique technological experience of being Amish, for example, have as much to do with the ability of such communities to sustain a quasi-democratic approach to technological change as the strength of their religious beliefs (see Wetmore 2007)? Such inquiries would demand deep engagement with psychology - in addition to areas of philosophy like post-phenomenology, a field STS scholars have more frequently treated as an object of study or target of critique than a full disciplinary partner. In any case, this line of research remains undone, despite the fact that a concern for the extent to which different technologies seem to practically necessitate or otherwise support only certain political orders was the central concern of Winner's (1980) "Do Artifacts Have Politics?" STS readers have seemingly preferred to quibble over Winner's more minor example of parkway overpasses (Joerges 1999) than engage his central thesis.

Why have investigations into technologies and their complex interrelations with political orders à la Winner remained undone? I wonder if STS as a field has something like a "dominant epidemiological paradigm" (Brown et al. 2001), which narrows the range of causative factors an analyst can appropriately consider when diagnosing what ails technological societies. Despite the influence of scholars like Winner, and Latour's (1992) call to the "missing masses," technology too often remains something to be explained in STS research via sociological or anthropological thought styles instead of a significant part of the explanation. In the same way that there seems to be too much convergence in lay thinking about technology and society, I wonder if there is far too much agreement among STS researchers about how to go about questioning technology.

Neither of the commentaries, furthermore, really took seriously my far less radical proposal to develop rhetorical tools-like broker frames, experience-taking, and parsimonious counter-narratives - in order to help partisans of democratic innovation persuade more people to see the democratization of technology as desirable and feasible. Hess (2015) and Raman (2015) seem to dismiss such tools as insufficiently holistic, complex, and democratic. I do not totally disagree with their concerns and reservations. However, I worry that "a habit of cultivating attention to complexity" (Raman 2015), though laudable much of the time, can become a barrier 
to action when overgrown. The development of potentially beneficial but recognizably imperfect tools and strategies is eschewed in favor of more rigorous forms of analysis that may, on the other hand, be less immediately translatable into action. The perfect becomes the enemy of the good-as one well-worn saying puts it.

Consider Ralph Nader's (2014) recent lament over the "applied bounty" of practical analysis benefiting progressive activists that could be delivered by social scientists but has yet to materialize. The excellent work cited by Hess and Raman notwithstanding, I think STS scholars' contribution to such an applied bounty could be bigger as well. Social movements looking for holes in the "opportunity structures" of contemporary neoliberal societies could still benefit from improved framings that better enroll fence sitters. Conservative or otherwise skeptical participants in deliberative forums might be pushed into greater thoughtfulness by narratives encouraging democratic "experience taking." Rather than dismiss such tools as too liable to fall prey to "culturalism" or failing to pass sufficient democratic muster, I think it would be valuable to explore potential synergies.

Such synergies are likely to remain invisible if STS scholars are unwilling to more often and broadly employ rhetorical tools like experience-taking and broker frames. Even though Hess's and Raman's critiques seem, at least partly, on target, I find myself skeptical of their predictions. Would STS-produced frames and counter-narratives necessarily draw political actors into a "self-defeating" "talking past each other?" Would too eagerly borrowing from psychology really result in "theory somnambulism?" It is hard to know for sure, but the analyses provided by Hess and Raman should at least signal that one is in risky territory.

How could enterprising STS scholars best proceed, given such risks? Because the rhetorical tools that I survey in my paper could be viewed as technologies, the literature on the governance of risky innovations offers an obvious starting point (Morone and Woodhouse 1986; Collingridge 1992; Woodhouse 2007). This literature emphasizes the limited ability of experts to accurately predict the consequences of implementing new technologies and hence the need to proceed strategically through intelligent trial and error in order to effectively learn from experience. Responsibly deploying new rhetorical tools would likely entail strategies similar to those used to minimize errors for and speed up feedback on new pesticides or genetic engineering techniques. Initial protective measures could include monitoring for "errors," such as failing to account for or include the least empowered or neglecting important structural factors. The deliberative "catastrophe" in which the employment of framings and counternarratives eventually devolves into an ideological "taking past each other" might be averted by more experimental testing: Under what conditions do different rhetorical tools impair deliberation rather than enhance it? Moreover, STS scholar-activists could demand the reasonable initial precaution that broker-frames and parsimonious counter-narratives are not to be deployed until such testing is done. Even after deployment, some protection against error would be assured by choosing to work with social movement groups that express a willingness to deploy rhetorical tools flexibly rather than "staying the course" whatever the cost. Given the relative lack of experience with such tools and the limited capacity of analytic brute strength to predict the 
eventual consequences, STS scholars could proceed strategically with these tools instead of not at all.

My critics' demands-for more attention to complexity, increased "holism," and more democratic engagement when considering how challenge technocratic governing mentalitiesare largely reasonable. However, such demands leave my proposal to draw upon and extend research from fields like social psychology "dead in the water" only if one presumes that it would be done with political and methodological carelessness and insensitivity. I appreciate Hess's and Raman's efforts to characterize the potential pitfalls in carrying my recommendations forward, even though they overlooked many important features of my argument. In any case, I hope that further debates taking place in the pages of this journal will help to diversify the range of methods, aims, forms of partisanship, and engagement strategies considered under the umbrella of "Doing STS."

\section{References}

Brown, P., S. Zavestoski, S. McCormick, M. Linder, J. Mandelbaum, and T. Luebke. 2001. "A Gulf of Difference." Journal of Health and Social Behavior 42(3):235-257.

Collingridge, D. 1992. The Management of Scale. New York, NY: Routledge.

Dafoe, A. 2015. “On Technological Determinism." Science, Technology, and Human Values 40 (6): 1047-1076. DOI: $10.1177 / 0162243915579283$.

Dotson, T. 2015. "Technological Determinism and Permissionless Innovation as Technocratic Governing Mentalities: Psychocultural Barriers to the Democratization of Technology."

Engaging Science, Technology, and Society 1: 98-120. DOI: http:/ / dx.doi.org/10.17351/ests2015.009.

Hess, D. J. 2015. "Power, Ideology, and Technological Determinism." Engaging Science, Technology, and Society. Engaging Science, Technology, and Society 1: 121-125. DOI: http:/ / dx.doi.org/10.17351/ ests2015.010.

Joerges, B. 1999. “Do Politics Have Artefacts?" Social Studies of Science 29(3): 411-431.

Latour, B. 1992. “Where Are the Missing Masses?" In Shaping Technology/Building Society, edited by John Law and Wiebe Bijker, 21-52. Cambridge, MA: MIT Press.

Lindblom, C. 1990. Inquiry and Change. New Haven, CT: Yale University Press.

Morone, J. G., and Edward J. Woodhouse. 1986. Averting Catastrophe. Berkeley, CA: University of California Press.

Nader, R. 2014. “Thanksgiving for Social Scientists." Huffington Post, November 26. Accessed December 8, 2014. http://www.huffingtonpost.com/ralph-nader/thanksgiving-forsocial-s_b_6225936.html.

Raman, S. 2015. "The Practices of Making Innovation Public." Engaging Science, Technology, and Society. Engaging Science, Technology, and Society 1: 126-130. DOI: http:// dx.doi.org/10.17351/ests2015.011.

Wetmore, J. M. 2007. “Amish Technology.” IEEE Technology and Society 26(2): 10-21. 
Winner, L. 1980. “Do Artifacts Have Politics?” Daedulus 109(1): 121-36

Woodhouse, E. J. 2007. "The Lessons of Katrina for Intelligent Public Decision Making." Nature and Culture 2(1): 10-26.

Wyatt, Sally. 2008. "Technological Determinism is Dead; Long Live Technological Determinism." In Handbook of Science and Technology Studies, 3 edition, edited by E. J. Hackett, O. Amsterdamsk, M. Lynch, and J. Wajcman, 165-180. Cambridge, MA: MIT Press. 